\title{
A FUZZY ANALYTIC HIERARCHY MODEL TO APPRAISE WATER ABSORPTION PROCESS PARAMETERS IN COCOA POD HUSK COMPOSITE
}

\author{
Isaac T. Abiola ${ }^{1}$ and Sunday A. Oke ${ }^{2}$ \\ ${ }^{1}$ Department of Mechanical Engineering, University of Lagos, Lagos, Nigeria. Email: \\ topetisaac@gmail.com \\ ${ }^{2}$ Department of Mechanical Engineering, University of Lagos, Lagos, Nigeria. Email: \\ sa_oke@yahoo.com (Corresponding author)
}

\section{HTTP://DX.DOI.ORG/10.30572/2018/KJE/120207}

\begin{abstract}
Water absorption characteristics of composites are crucial to robust composite design with integrity and long service lives. In the literature, scholars have evaluated the water absorption properties of cocoa pod husk composites but reports regarding their uncertainty and imprecision are missing. In this article, cocoa pod husk particulate reinforced composite material was analyzed for uncertainty and imprecision using the fuzzy analytic process to rank and select the important parameters of the water absorption process. Experimental data from a project were collected and analyzed considering particulate loading, initial weight, particulate weight, the weight of the matrix, weight gained after 150 days and rate of water absorption as parameters. The parameters were sensitive and active and the findings provide new procedures to analyze thermoset composites under the circumstances of uncertainty and imprecision. This work aids to effectively produce composites of integrity, long lifespan and retain customers in the competitive composite market.
\end{abstract}

\section{KEYWORDS}

Cocoa pod husk, multi-criteria, decision making, uncertainty, water absorption 


\section{INTRODUCTION}

In marine-oriented composites, water absorption tests are used to analyze the integrity of the composites regarding their mechanical, wear and corrosive properties before full-scale manufacturing (Karthick et al., 2018; Saxena and Gupta, 2018; Aydemir et al., 2019; Kusmono et al., 2020). Knowledge on the performance of composites in water media provides ideas to design engineers and fabricators on structural (re)design and computations concerning composite parameters (Daramola et al., 2019; Yu et al., 2020). Hence, their service capability is enhanced as well as their maintenance costs. Furthermore, their water resistance is improved and their lifespan also increases. Therefore, water absorption tests of thermoset polymer composites are essential for sustenance and growth of the industry. However, from the literature review, it was discovered that researchers have attempted to discuss the water absorption properties of cocoa pod husk composite (Ehi et al., 2016). But the importance rating of the key parameters in the process considering the uncertainly and imprecision involved in the water absorption process has not been reported (Imoisili et al., 2013a,b; El-Shekeil et al., 2014; Chun and Husseinsyah, 2014; Chun et al., 2013, 2017; Ehi et al., 2016; Sanyang et al., 2017).

In the design and fabrication of marine-based composites, the use of the traditional analytic hierarchy process lacks the aptitude to tackle imprecision subjectivity in the judgments by designers and fabricators concerning the parameters of the composite (Bozbura and Beskese, 2007; Chan and Kumar, 2007; Ebrahimi and Bridgelall, 2020; Park et al., 2020; Wei et al., 2020; Song et al., 2021). Consider the initial weight of the reinforcement as an object of interest. The Mxbaocheng digital weighting balance of capacity to measure up to $1000 \mathrm{~g}$ with precision to $0.01 \mathrm{~g}$ is an option to use in measuring the cocoa pod husk reinforcement. However, there is inherent uncertainty in the measurement system. A specific measured value of reinforcement on a rainy morning may be different from the measured value in a sunny afternoon due to environmental changes of pressure, temperature and humidity of the laboratory. Furthermore, since the measurement aspect is not limited to only a member of the research team, at times, the measurement equipment may be used improperly while the sources of error are ignored. Every kind of measurement has uncertainty regarding it. Since it is challenging to eradicate error the aim must be to evaluate it and lessen it to a suitable value in the context of taking measurements.

Arising from this argument, the novelty of this article is to suggest a new method to water absorption process parametric evaluation to establish the uncertainty in the evaluation of the key parameters of water absorption for a collected data from the laboratory experiment on cocoa pod husk composites. To attain this, the fuzzy analytic hierarchy process is deployed where the 
parametric characteristics are described in linguistic terms by membership functions in a fuzzification exercise (Ebrahimi and Bridgelall, 2020; Park et al., 2020; Wei et al., 2020; Song et al., 2021). Subsequently, the pairwise comparison, fuzzy weight determination, defuzzification and normalisation are done (Park et al., 2020; Song et al., 2021). The new approach is then applied to data collected from the laboratory on water absorption experiments regarding cocoa pod husk composites. Then the results are analyzed and discussed.

A brief review of the relevant literature will offer some insights into the problem being solved. Imoisili et al. (2013) examined the mechanical attributes of cocoa pod composites and the influence of various filler volume fractions on the mechanical characteristics. It was concluded that a decline in flexural and tensile strength of the composite with volume fraction decrease. However, growth in flexural modulus, tensile modulus and micro-hardness were experienced with growth in filler volume fraction. Imoisili et al. (2013b) examined the physicochemical attributes of cocoa pod composites. The results showed values for moisture, ash, lignin, cellulose and extractive contents as $6.69 \%, 8.91 \%, 26.51 \%, 24.28 \%$ and $4.81 \%$, correspondingly. The decline of the tensile and specific strength and percentage elongation with volume composition of the fillers was experienced. However, the contrary results were obtained when modulus and specific modulus were related to volume composition as growth on one side was mapped to growth on the other side. Chun et al. (2013) analyzed the influence of filler modification with methacrylic acid on polypropylene-cocoa pod husk composites. It was ascertained that the methacrylic acid enhanced the composites stabilization torque, their tensile strength and modulus. Chun and Husseinsyah (2014) experimented with cocoa pod husk composites with chemical treatments and different chemical composition. They concluded that with treatment regarding 3-mercaptopropyltrimethoxsilane and sodium dodecylsulphate, enhancement in the thermal stability crystallinity, tensile strength, water resistivity, tensile modulus and stabilization torque existed. El-Shekeil et al. (2014) produced cocoa pod husk composites in various filler compositions $(20 \%, 30 \%$ and $40 \%$ by weight) and engaged optimum processing parameters regarding speed, temperature and time as $40 \mathrm{rpm}, 190^{\circ} \mathrm{C}$ and $11 \mathrm{~min}$, correspondingly. It was concluded that growth in fibre loading triggered growth in tensile strength as well as modulus and decline in the pattern of strain.

Ehi et al. (2016) studied the kinetic attributes of cocoa pod husk composites and their influence on water absorption characteristics of the composites while varying the volume fraction of the filler. The conclusion was that the diffusion coefficient, a key Fick's model parameter was obtained at $105.8 \times 10^{-7} \mathrm{~m}^{2} / \mathrm{s}$ at $30 \%$ volume fraction. It was confirmed that the water absorption process yielded to Fick's law. Puglia et al. (2016) conducted a three-phase characterisation of 
cocoa been shell composites to include morphological, thermal and tensile tests. The reported result was an improved rigidity with a marginal decline in strength regarding neat polymer. A lessened elongation was experienced at $30 \mathrm{wt} \%$ composite. At this point, the eventual collapse occurred for strains merely marginally surpassing the yield point. Olabisi et al. (2016) developed cocoa been shell composites for brake pad application and established their attributes regarding physical, tribological and mechanical aspects. It was reported that the decline in filler composition stimulated growth in wear rate, compressive strength and tensile strength. Conversely, oil absorption, density, thermal conductivity and hardness responded differently. Chun et al. (2017) examined the rheological characteristics of polypropylene/cocoa pod husk composites and considered the following attributes - the influence of processing parameter, modification of content by maheated propylene treatment agent addition, and filler composition and their association with torque rheological attributes. The processing torque was established to grow with the growth in filler composition, rotor speed and the addition of the chemical treatment. The melt attributes of the composites were confirmed at superior shear rate. This behaviour was coupled with shear thinning. Furthermore, the power-law index declined as the growth of filler composition and addition of the chemical treatment occurred. Sanyang et al. (2017) examined the influence of cocoa pod husk loading on the tensile attributes of the composite. The conclusion was that growth in the tensile strength accompanied the growth in filler loading up to $10 \%$ loading but outside this range, the elongation at break declined.

Chun et al.'s (2018) contribution to cocoa pod husk development had an emphasis on green coupling mediator. Notwithstanding, explanations on the strength of the agent were given from the viewpoint of spread for the customized cocoa pod husk particulates and their superior interfacial relationship with the matrix, which yield substantial composite property enhancement. The interest of Olatundun et al. (2020) in the use of cocoa pod husk was a route to economic prosperity. By combining this agro-waste with a blend of plantain peels, the researchers achieved their aim. In Azmin et al. (2020), the concern for use of cocoa pod husk in food packaging was examined.

From the above review, it was observed that no study has discussed the ordering and selection of the important water absorption parameters for cocoa pod husk composites under uncertainty and imprecision. This research gap has motivated the necessity to rank and select the key water absorption parameters of cocoa pod husk composites and apply the fuzzy analytic hierarchy process technique to it. Apart from particulate loading, there are other parameters, including particulate weight, initial weight, the weight of the matrix, weight gained after 150 days and rate of water absorption that also influence the water absorption behaviour of the composite. 
Consequently, it is essential to rank these parameters against particulate loading. If the particulate loading of the cocoa pod husk composite varies then the mentioned parameters are influenced and consequently, it is essential to rank these parameters together with particulate loading.

The earlier studies in this specific knowledge domain are Ehi et al. (2016) and Ayanladun and Oke (2020). While Ehi et al. (2016) analyzed the kinetics of water absorption, the concern of Ayanladun and Oke (2020) was the sensitivity analysis tests of parameters. Although these studies advanced knowledge on water absorption on cocoa pod composites, the gap concerning uncertainty and imprecision still remains unsolved. The study by Ayanladun and Oke (2020) while recognizing the importance of extended particulate loading scope tried to span the study from $1 \mathrm{wt} \%$ to $31 \mathrm{wt} \%$ in steps of 2 . However, the period of composite immersion is still limited to about 70 days, which may be further extended since the case of marine applications may involve longer stay of ships, for instance in water and the ship's hull may have contact with the water bodies for long periods. Thus, a novel feature of the present paper is the extension of the period of analysis by a multiple of 2.143 of the study by Ayanladun and Oke (2020). That is, this study spans for 150 days.

Besides, the ranking techniques within the multi-criteria context used for composite parametric ranking include the analytic hierarchy process (Onyegiri and Oke, 2016; Raji and Oke, 2020). But fuzzy analytical hierarchy process using geometric mean approach has not been deployed to solve this water absorption parametric determination problem. Interestingly, fuzzy analytic hierarchy process has merits regarding its huge similarity with the traditional analytic hierarchy process method (Ighravwe and Oke, 2017; Ebrahimi and Bridgelall, 2020; Park et al., 2020; Wei et al., 2020; Song et al., 2021). It comprises of fuzzy pairwise comparison, matrix defuzzification, computation of consistency ratio, weight determination among other elements, to the choice of the preferred option. Keeping in mind the intrinsic attributes of fuzzy analytic hierarchy to attain robust ranking and selection of parameters, it is used in the current study to establish the ranks of water absorption parameters for cocoa pod husk composites.

\section{METHODS}

A robust procedure on the fuzzy analytic hierarchy process (FAHP) is presented in Park et al. (2020) in eight phases compressed to six here. As presented by Park et al. (2020), AHP prides in its ability to offer superior decision-making framework weighed against the AHP as it is more accurate. This procedure is mentioned based on the work presented by Park et al. (2020) as follows. The premier step involves an appraisal of every standard and entries of the topic. They were afterwards positioned in a hierarchical framework. The second step involves an 
appraisal of entries and subcriteria, which are weighed against one another to achieve match up assessment at each echelon of hierarchy. The third step involves the translation of the matrix containing the matched up assessment to triangular fuzzy values. The fourth step has orientation around how the fuzzy extent value is computed by employing the matrix that was translated into triangular fuzzy value. In step five, the fuzzy extent value for the degree of possibility is attained. Step six contains actions to normalise the degree of possibility the comparative significance of each hierarchical rank, the upper rank and associated sub-hierarchy rank multiplication as well as how to attain preference.

2.1 The use of AHP method to solve the problem

For comparison of the FAHP method, the procedure for the AHP method is established here.

Step 1 Build up a hierarchical framework revealing the goal of the water absorption process regarding composite manufacture at the top level, the criteria displayed at the second level and the options shown at the third level (Fig. 1).

Step 2 Establish the relative importance of different attributes regarding the goal of the cocoa pod husk composite production. To achieve this, a pairwise comparison matrix is developed.

Pairwise comparison matrix is achieved by generating a scale of comparative importance according to Satty's importance scale: 
$1 / 3, \quad 1 / 5$, Values for inverse

$1 / 7,1 / 9 \quad$ comparison
Scale of comparative significance

$\begin{array}{llll}3 & \text { Moderate interest } & 5 & \text { Strong interest } \\ 9 & \text { Extreme interest } & 2,4,6,8 & \text { Intermediate values }\end{array}$

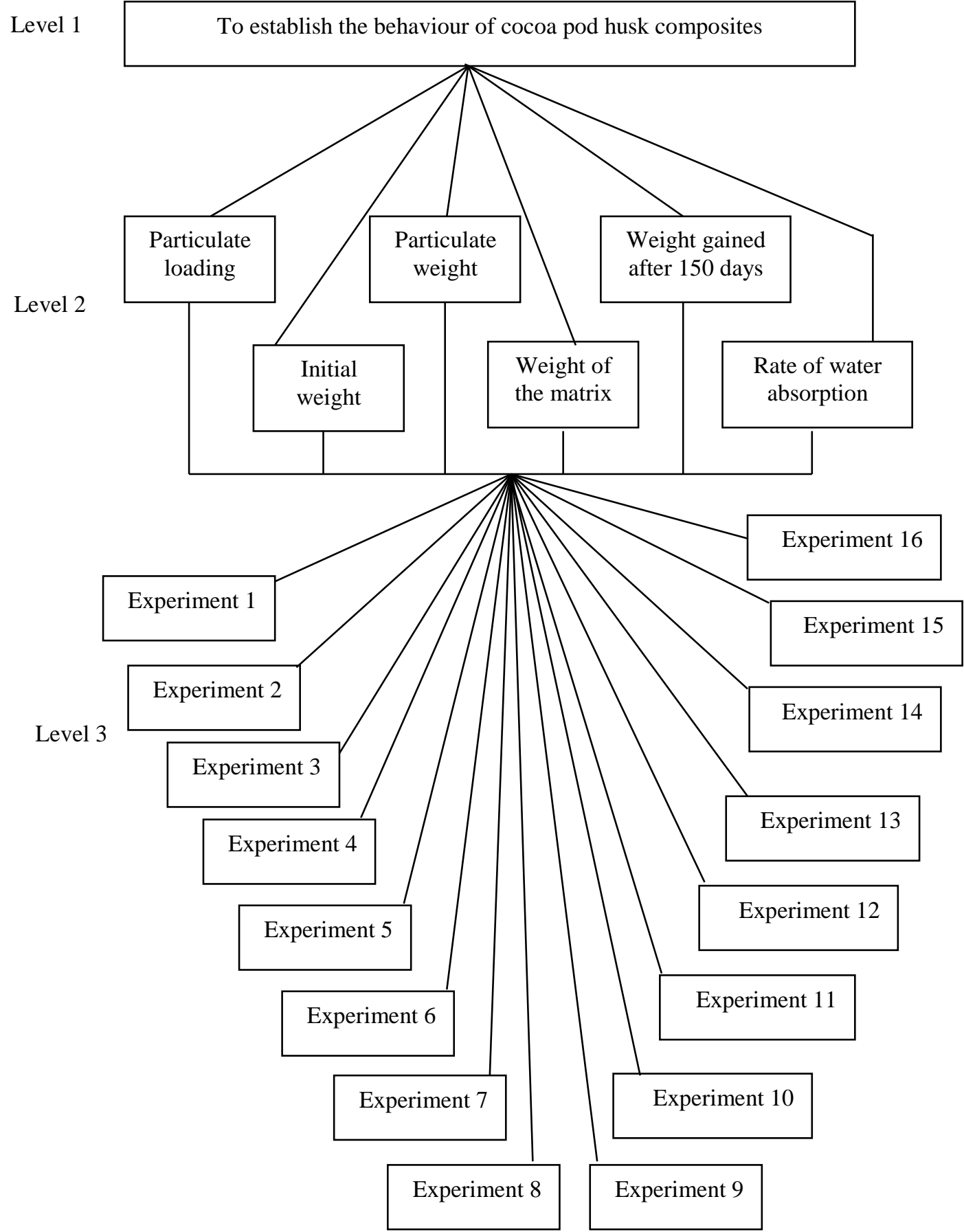

Fig. 1. AHP hierarchical structure for water absorption parameters of cocoa pod husk composite 
Step 3 Decision making

Step 4 Converting the factional values to decimal values and summing up all the values in each column.

Step 5 Calculate the normalised pairwise matrix. All the elements of the colum are each divided by the sum of the columns.

Step 6 Calculate the criteria weight. This is achieved by adding all the elements in the row and dividing each by the number of criteria

\section{RESULTS AND DISCUSSION}

The most important step in AHP is to create the pairwise comparison matrix which evolves with the assistance of the scale of comparative importance. The numbers in relative importance are strictly numeric values such as 1, 3, 5, 7 and 9. In fuzzy, this numeric values are converted into fuzzy numbers. There are various terms that need explanation in adopting fuzzy analytic hierarchy process to the cocoa pod husk composite evaluation for water absorption process parameter establishment. First is the term fuzzification. By converting linguistic terms into membership function the triangular shape (Fig. 2) is used to create the membership function.

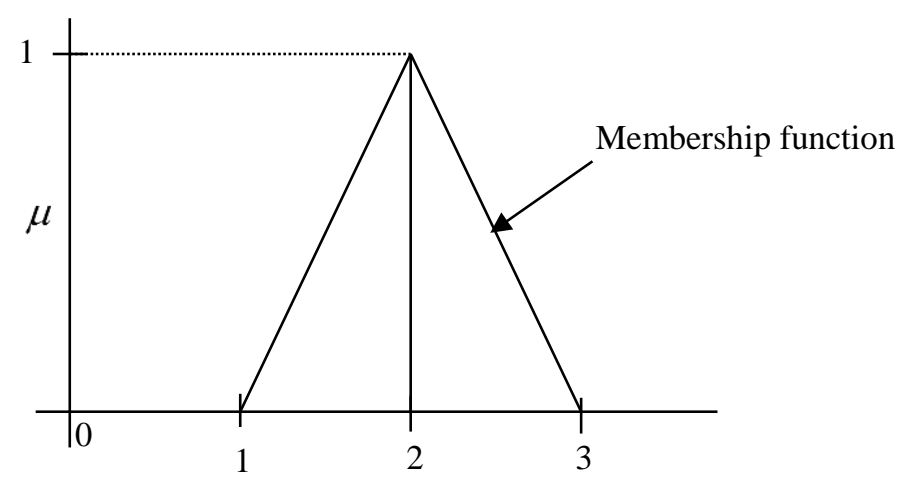

Fuzzy numbers

Fig. 2. Membership function of parameters for the cocoa pod husk composite for water absorption process

As the shape of the membership function is triangular it is known as triangular membership function. Other shapes may include the trapezoidal and bell shaped membership functions. The fuzzy value is represented by $\mu_{\bar{A}}(x)$. Notice that $\mu_{A}(x)=\bar{A}=(1,2,3)$ means that there are three numbers, which are 1,2 and 3 and are known as fuzzy numbers. They are associated with the membership function. These numbers indicate the upper, middle and lower function. 

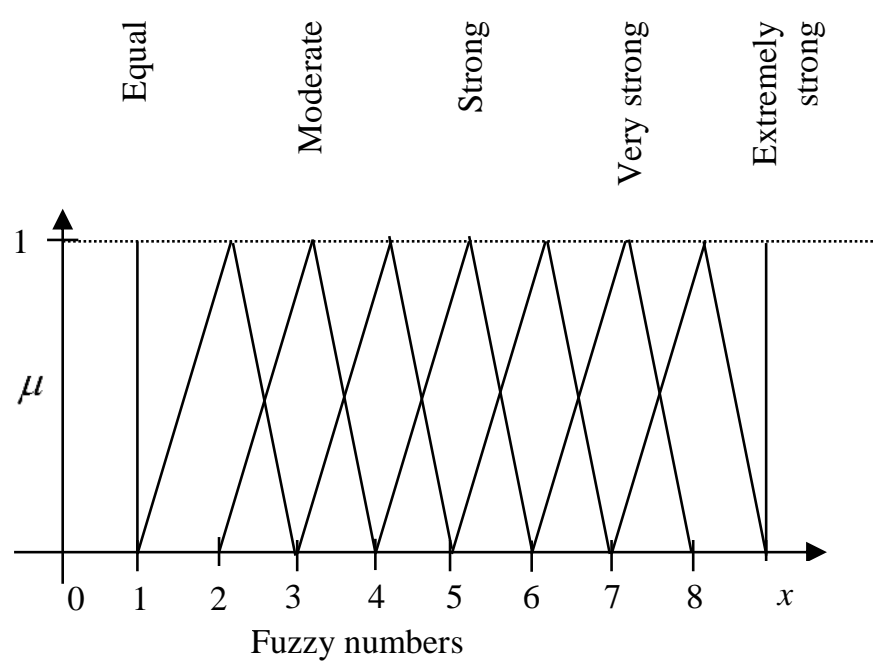

Fig. 3. Membership function of parameters for the cocoa pod husk composite for water absorption process (fuzzy scale).

Fuzzy scale of relative importance

Equal 1; Moderate 3; Strong $\quad$ 5; Very strong 7; Extremely strong 9; Intermediate values $2,4,6,8$

Crisp numbers in the scale of relative importance $(1,3,5,7,9)$ are replaced with fuzzy numbers (Fig. 3). It is seen that assigning a single number to any term was not justified. For instance, moderate has been assigned the value of 3 but what do we call 2.5 or 3.5? To solve this issue, the concept of fuzzy numbers will be introduced (Table 1).

Table 1. Introducing fuzzy numbers.

\begin{tabular}{ccc}
\hline Description & Scale of relative importance & Fuzzy numbers \\
\hline Equal & 1 & $(1,1,1)$ \\
\hline Moderate & 3 & $(2,3,4)$ \\
\hline Strong & 5 & $(4,5,6)$ \\
\hline Very strong & 7 & $(6,7,8)$ \\
\hline Extremely & 9 & $(9,9,9)$ \\
strong & 2 & $(1,2,3)$ \\
\hline & & $(3,4,5)$ \\
Intermediate & 4 & $(5,6,7)$ \\
values & 6 & $(7,8,9)$ \\
& 8 &
\end{tabular}


Convert the crisp values in Table 1 into fuzzy numbers with the help of the conversion rate in Table 2.

Table 2. Fuzzification pairwise comparison matrix for the cocoa pod husk composite.

\begin{tabular}{ccccccc}
\hline Parameter & $\begin{array}{c}\text { Particulate } \\
\text { loading }\end{array}$ & $\begin{array}{c}\text { Initial } \\
\text { weight }\end{array}$ & $\begin{array}{c}\text { Particulate } \\
\text { weight }\end{array}$ & $\begin{array}{c}\text { Weight } \\
\text { of } \\
\text { matrix }\end{array}$ & $\begin{array}{c}\text { Weight } \\
\text { gained after } \\
150 \text { days }\end{array}$ & $\begin{array}{c}\text { Rate of } \\
\text { water } \\
\text { absorption }\end{array}$ \\
\hline $\begin{array}{c}\text { Particulate } \\
\text { loading }\end{array}$ & $(1,1,1)$ & $(4,5,6)$ & $(3,4,5)$ & $(1,2,3)$ & $(6,7,8)$ & $(9,9,9)$ \\
\hline Initial weight & $1 / 5$ & $(1,1,1)$ & $(2,3,4)$ & $(3,4,5)$ & $(5,6,7)$ & $(7,8,9)$ \\
\hline $\begin{array}{c}\text { Particulate } \\
\text { weight }\end{array}$ & $1 / 4$ & $1 / 3$ & $(1,1,1)$ & $(4,5,6)$ & $(7,8,9)$ & $(6,7,8)$ \\
\hline $\begin{array}{c}\text { Weight of } \\
\text { matrix }\end{array}$ & $1 / 2$ & $1 / 4$ & $1 / 5$ & $(1,1,1)$ & $(4,5,6)$ & $(5,6,7)$ \\
\hline $\begin{array}{c}\text { Weight gained } \\
\text { after 150 days }\end{array}$ & $1 / 7$ & $1 / 6$ & $1 / 8$ & $1 / 5$ & $(1,1,1)$ & $(7,8,9)$ \\
\hline $\begin{array}{c}\text { Rate of water } \\
\text { absorption }\end{array}$ & $1 / 9$ & $1 / 8$ & $1 / 7$ & $1 / 6$ & $1 / 8$ & $(1,1,1)$ \\
\hline
\end{tabular}

Converting the reciprocal value into fuzzy number using (Table 3):

$\tilde{A}^{-1}=(l, m, u)^{-1}=\left(\frac{1}{u}, \frac{1}{m}, \frac{1}{l}\right)^{-1}$

Table 3. Fuzzification pairwise comparison matrix for the cocoa pod husk composite (translation1).

\begin{tabular}{lllllll}
\hline $\begin{array}{l}\text { Parameter } \\
\text { loading }\end{array}$ & $\begin{array}{l}\text { Particulate } \\
\text { weight }\end{array}$ & $\begin{array}{l}\text { Pnitial } \\
\text { weight }\end{array}$ & $\begin{array}{l}\text { Weight of } \\
\text { matrix }\end{array}$ & $\begin{array}{l}\text { Weight } \\
\text { gained after } \\
150 \text { days }\end{array}$ & $\begin{array}{l}\text { Rate of } \\
\text { water } \\
\text { absorption }\end{array}$ \\
\hline $\begin{array}{l}\text { Particulate } \\
\text { loading }\end{array}$ & $(1,1,1)$ & $(4,5,6)$ & $(3,4,5)$ & $(1,2,3)$ & $(6,7,8)$ & $(9,9,9)$ \\
\hline $\begin{array}{l}\text { Initial } \\
\text { weight }\end{array}$ & $\left(\frac{1}{6}, \frac{1}{5}, \frac{1}{4}\right)$ & $(1,1,1)$ & $(2,3,4)$ & $(3,4,5)$ & $(5,6,7)$ & $(7,8,9)$ \\
\hline $\begin{array}{l}\text { Particulate } \\
\text { weight }\end{array}$ & $\left(\frac{1}{5}, \frac{1}{4}, \frac{1}{3}\right)$ & $\left(\frac{1}{4}, \frac{1}{3}, \frac{1}{2}\right)$ & $(1,1,1)$ & $(4,5,6)$ & $(7,8,9)$ & $(6,7,8)$ \\
\hline $\begin{array}{l}\text { Weight of } \\
\text { matrix }\end{array}$ & $\left(\frac{1}{3}, \frac{1}{2}, \frac{1}{1}\right)$ & $\left(\frac{1}{5}, \frac{1}{4}, \frac{1}{3}\right)$ & $\left(\frac{1}{6}, \frac{1}{5}, \frac{1}{4}\right)$ & $(1,1,1)$ & $(4,5,6)$ & $(5,6,7)$ \\
\hline $\begin{array}{l}\text { Weight } \\
\text { gained } \\
\text { after 150 } \\
\text { days }\end{array}$ & $\left(\frac{1}{8}, \frac{1}{7}, \frac{1}{6}\right)$ & $\left(\frac{1}{7}, \frac{1}{6}, \frac{1}{5}\right)$ & $\left(\frac{1}{9}, \frac{1}{8}, \frac{1}{7}\right)$ & $\left(\frac{1}{6}, \frac{1}{5}, \frac{1}{4}\right)$ & $(1,1,1)$ & $(7,8,9)$ \\
\hline $\begin{array}{l}\text { Rate of } \\
\text { water } \\
\text { absorption }\end{array}$ & $\left(\frac{1}{9}, \frac{1}{7}, \frac{1}{8}\right)$ & $\left(\frac{1}{9}, \frac{1}{8}, \frac{1}{7}\right)$ & $\left(\frac{1}{8}, \frac{1}{7}, \frac{1}{6}\right)$ & $\left(\frac{1}{7}, \frac{1}{6}, \frac{1}{5}\right)$ & $\left(\frac{1}{9}, \frac{1}{8}, \frac{1}{7}\right)$ & $(1,1,1)$ \\
\hline
\end{tabular}


Using the FAHP proposed by Buckley in the year 1985 in which geometry mean is used to calculate the weight, calculating the fuzzy geometric mean value is obtained using the formula:

$$
\tilde{\tilde{A}}_{1} \otimes \tilde{A}_{2}=\left(l_{1}, m_{1}, u_{1} \otimes l_{2}, m_{2}, u_{2}\right)=\left(l_{1} \times l_{2}, m_{1} \times m_{2}, u_{1} \times u_{2}\right)
$$

For the first parameter, the computation proceeds as follows:

$$
\tilde{r}_{1}=\left((1 \times 4 \times 3 \times 1 \times 6 \times 9)^{\frac{1}{6}},(1 \times 5 \times 4 \times 2 \times 7 \times 9)^{\frac{1}{6}},(1 \times 6 \times 5 \times 3 \times 8 \times 9)^{\frac{1}{6}}\right)=(2.94,3.69,4.32)
$$

Similary, other values such as $\underset{r_{2}}{\approx}, \tilde{r}_{3}$ and $\tilde{r}_{4}$ are obtained an inserted in Table 4.

Table 4. Fuzzy geometric mean values.

\begin{tabular}{cc}
\hline Parameter & Fuzzy geometric mean values \\
\hline Particulate loading & $(2.94,3.69,4.32)$ \\
\hline Initial weight & $(1.81,2.14,2.61)$ \\
\hline Particulate weight & $(1.43,1.09,2.04)$ \\
\hline Weight of matrix & $(0.78,0.95,1.23)$ \\
\hline Weight gained after 150 days & $(0.26,0.41,0.47)$ \\
\hline Rate of water absorption & $(0.17,0.19,0.20)$
\end{tabular}

To calculate the fuzzy weight, we use the formula:

$$
\tilde{\omega}_{i}=\tilde{r}_{i} \otimes\left(\tilde{r}_{1} \otimes \tilde{r}_{2} \otimes \ldots \tilde{r}_{n}\right)^{-1}
$$

Adding fuzzy geometric mean value with the formula:

$$
\begin{gathered}
\tilde{\tilde{A}}_{1} \otimes \tilde{A}_{2}=\left(l_{1}, m_{1}, u_{1} \otimes l_{2}, m_{2}, u_{2}\right)=\left(l_{1} \times l_{2}, m_{1} \times m_{2}, u_{1} \times u_{2}\right), \text { we obtain } \\
2.94+1.81+1.43+0.78+0.36+0.17=7.49 \\
3.69+2.14+1.69+0.95+0.41+0.19=9.07 \\
4.32+2.62+2.04+1.23+0.47+0.20=10.87
\end{gathered}
$$

$$
\approx \tilde{r}_{i} \otimes \tilde{r}_{2} \otimes \tilde{r}_{3} \otimes \tilde{r}_{4} \otimes \tilde{r}_{5} \otimes \approx \tilde{r}_{6}=(7.49,9.07,10.87)
$$

But $\left(\tilde{r_{i}} \otimes \tilde{r}_{2} \otimes \tilde{r_{3}} \otimes \tilde{r}_{4} \otimes \tilde{r}_{5} \otimes \tilde{r}_{6}\right)^{-1}=\tilde{A}^{-1}=(l, m, u)^{-1}=\left(\frac{1}{u}, \frac{1}{m}, \frac{1}{l}\right)^{-1}=\left(\frac{1}{10.87}, \frac{1}{9.07}, \frac{1}{7.49}\right)$

To calculate fuzzy weight, we use the formula (Table 5): 
Table 5. Fuzzy weights for parameters.

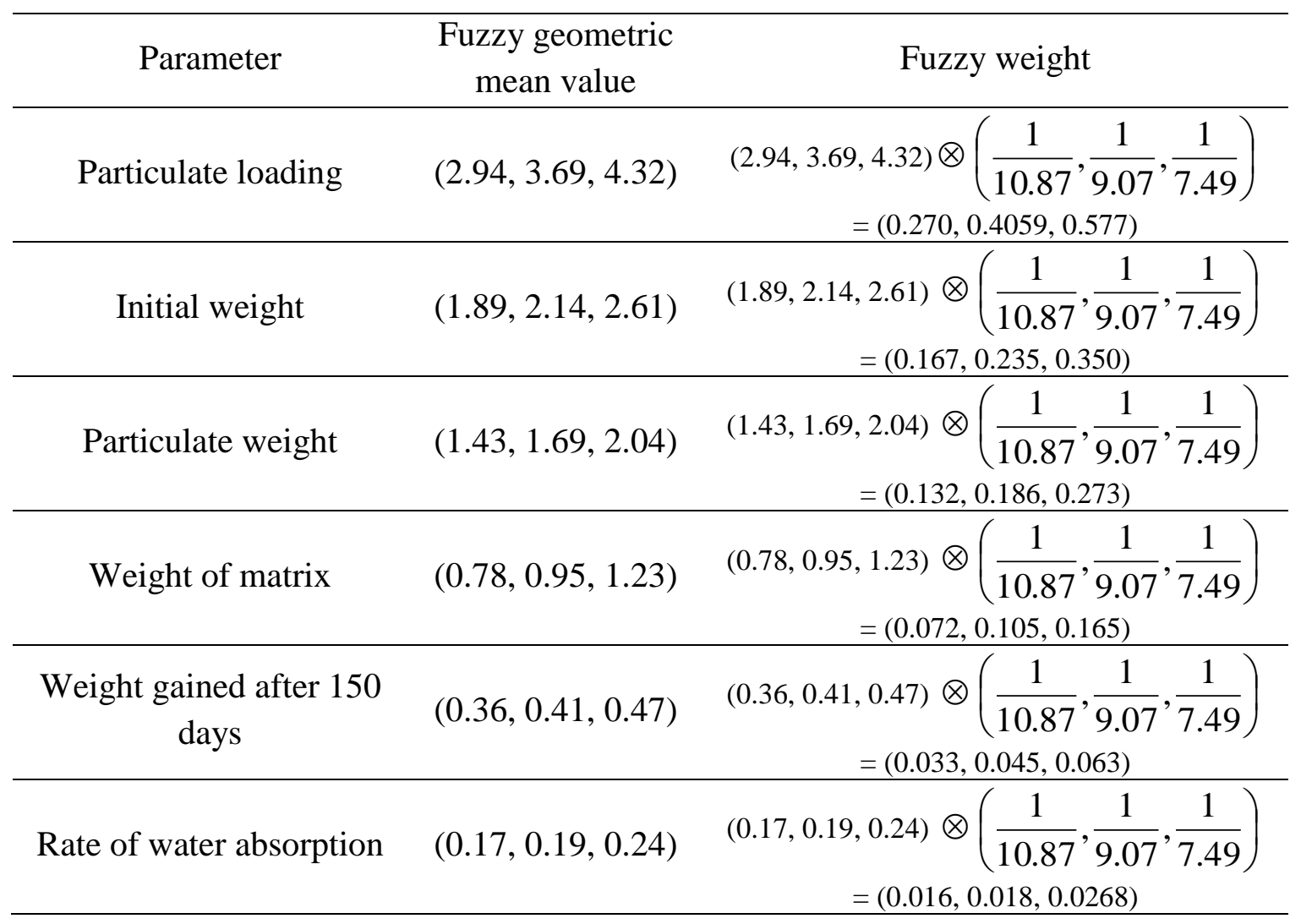

To obtain defuzzified values for the parameters, the expression for $w_{j}$ is used (Table 6):

$$
W_{j}=(l+m+n) / 3
$$

Table 6. Defuzzification of parametric values.

\begin{tabular}{ccc}
\hline Parameter & Fuzzy weight $\left(w_{j}\right)$ & Weight $\left(w_{j}\right)$ \\
\hline Particulate loading & $(0.270,0.406,0.577)$ & 0.418 \\
\hline Initial weight & $(0.167,0.235,0.350)$ & 0.251 \\
\hline Particulate weight & $(0.132,0.186,0.273)$ & 0.197 \\
\hline Weight of matrix & $(0.072,0.105,0.165)$ & 0.114 \\
\hline $\begin{array}{c}\text { Weight gained after 150 } \\
\text { days }\end{array}$ & $(0.033,0.045,0.063)$ & 0.042 \\
\hline Rate of water absorption & $(0.016,0.015,0.027)$ & 0.020 \\
\hline
\end{tabular}

Summation of weightage

The sum of weightage becomes 1.047 from the component elements of $0.4176,0.251,0.197$, $0.114,0.047$ and 0.0203 . The result of weight is greater than 1 , which makes it unacceptable. 
Therefore there is need to normalise the weight by obtaining each weight by the sum of weight. The outcome of normalisation is shown as follows (Table 7):

Table 7. Normalised weights of parameters

\begin{tabular}{lll}
\hline Parameter & Weight $\left(w_{j}\right)$ & Normalised weight \\
\hline Particulate loading & 0.4176 & 0.399 \\
\hline Initial weight & 0.251 & 0.240 \\
\hline Particulate weight & 0.197 & 0.188 \\
\hline Weight of matrix & 0.114 & 0.109 \\
\hline Weight gained after 150 days & 0.047 & 0.045 \\
\hline Rate of water absorption & 0.0203 & 0.0194 \\
\hline
\end{tabular}

\section{COMPARISON OF THE PRESENT STUDY WITH THE AHP METHOD}

This study introduces a fuzzy analytic hierarchy process as an intervention tool to identify the strength of the parameters regarding cocoa pod husk composites tested through water absorption process experiments. Experimental data were obtained from a larger project. To demonstrate the competence of the approach, this paper utilized an example by applying the data to the analytic hierarchy process (AHP) method. The numerical results obtained in the present study were compared with the results that were computed using the AHP method. Some statistical analysis provided insights into the similarities and differences between the two output categories.

It is desired to evaluate the weightage of each parameter and this effort begins by transforming the data into a $6 \times 6$ matrix. Afterwards, six steps are followed in the use of AHP method to solve the problem.

Step 1 Build up a hierarchical framework revealing the goal of the water absorption process regarding composite manufacture at the top level, the criteria displayed at the second level and the options shown at the third level (Fig. 1).

Step 2 Establish the relative importance of different attributes regarding the goal of the cocoa pod husk composite production. To achieve this, a pairwise comparison matrix is developed.

The length of the pairwise matrix is equivalent to the number of criteria used in the decision making process. Consequently, this paper adopts a 6 × 6 matrix in the evaluation of the ranks for different parameters using the AHP. 


\section{Step 3 Decision making}

Particulate loading was taken to be of strong interest to initial weight. Consequently, if it is assumed that the initial weight is "q", then particulate loading will be " $5 \mathrm{q}$ " value. Thus the row element with the column element divided. So the association between particulate loading and initial weight equals $5 \mathrm{q} / \mathrm{q}=5$. This is the division of the row element to the column element while the value for the inverse yields $1 / 5$.. Next, the particulate loading is compared with particulate weight. Here, particulate loading is of moderate to strong interest when compared with particular weight. So, there is a value a value in-between 3 and 5, which is 4 . Consequently, if particulate weight is $q$ value then particulate loading equals $4 q$, and $4 q / q=4$. The value for the inverse comparison is $1 / 4$. With this procedure followed, the $6 \times 6$ matrix is constructed (Table 8).

Table 8. The $6 \times 6$ matrix representing the values of the pairwise comparison for the cocoa pod husk composite.

\begin{tabular}{ccccccc}
\hline Parameter & $\begin{array}{c}\text { Particulate } \\
\text { loading }\end{array}$ & $\begin{array}{c}\text { Initial } \\
\text { weight }\end{array}$ & $\begin{array}{c}\text { Particulate } \\
\text { weight }\end{array}$ & $\begin{array}{c}\text { Weight } \\
\text { of } \\
\text { matrix }\end{array}$ & $\begin{array}{c}\text { Weight } \\
\text { gained after } \\
150 \text { days }\end{array}$ & $\begin{array}{c}\text { Rate of } \\
\text { water } \\
\text { absorption }\end{array}$ \\
\hline $\begin{array}{c}\text { Particulate } \\
\text { loading }\end{array}$ & 1 & 5 & 4 & 2 & 7 & 9 \\
\hline $\begin{array}{c}\text { Initial } \\
\text { weight }\end{array}$ & $1 / 5$ & 1 & 3 & 4 & 6 & 8 \\
\hline $\begin{array}{c}\text { Particulate } \\
\text { weight }\end{array}$ & $1 / 4$ & $1 / 3$ & 1 & 5 & 8 & 7 \\
\hline $\begin{array}{c}\text { Weight of } \\
\text { matrix }\end{array}$ & $1 / 2$ & $1 / 4$ & $1 / 5$ & 1 & 5 & 8 \\
\hline $\begin{array}{c}\text { Weight } \\
\text { gained } \\
\text { after } 150 \\
\text { days }\end{array}$ & $1 / 7$ & $1 / 6$ & $1 / 8$ & $1 / 5$ & 1 & 1 \\
\hline $\begin{array}{c}\text { Rate of } \\
\text { water } \\
\text { absorption }\end{array}$ & $1 / 9$ & $1 / 8$ & $1 / 7$ & $1 / 6$ & $1 / 8$ & \\
\hline
\end{tabular}

In Table 8, the diagonal elements take the value of 1 because particulate loading will be of equal interest to particulate loading, for example. Similarly, initial weight will be of equal interest to initial weight, particulate weight will be of equal interest to particulate weight, and the rest is computed in a similar manner. 
Step 4 Converting the factional values to decimal values and summing up all the values in each column (Table 9).

Table 9. The $6 \times 6$ matrix representing the values of the pairwise comparison for the cocoa pod husk composite.

\begin{tabular}{ccccccc}
\hline Parameter & $\begin{array}{c}\text { Particulate } \\
\text { loading }\end{array}$ & $\begin{array}{c}\text { Initial } \\
\text { weight }\end{array}$ & $\begin{array}{c}\text { Particulate } \\
\text { weight }\end{array}$ & $\begin{array}{c}\text { Weight } \\
\text { of } \\
\text { matrix }\end{array}$ & $\begin{array}{c}\text { Weight } \\
\text { gained } \\
\text { after } 150 \\
\text { days }\end{array}$ & $\begin{array}{c}\text { Rate of } \\
\text { water } \\
\text { absorption }\end{array}$ \\
\hline Particulate loading & 1 & 5 & 4 & 2 & 7 & 9 \\
\hline Initial weight & 0.200 & 1 & 3 & 4 & 6 & 8 \\
\hline Particulate weight & 0.250 & 0.333 & 1 & 5 & 8 & 7 \\
\hline Weight of matrix & 0.500 & 0.250 & 0.200 & 1 & 5 & 6 \\
\hline $\begin{array}{c}\text { Weight gained after } \\
\text { 150 days }\end{array}$ & 0.143 & 0.160 & 0.125 & 0.200 & 1 & 8 \\
\hline $\begin{array}{c}\text { Rate of water } \\
\text { absorption }\end{array}$ & 0.110 & 0.125 & 0.143 & 0.160 & 0.125 & 1 \\
\hline Sum & 2.203 & 6.863 & 8.644 & 12.36 & 27.13 & 39 \\
\hline
\end{tabular}

Step 5 Calculate the normalised pairwise matrix. All the elements of the colum are each divided by the sum of the columns (Table 10).

Table 10. The $6 \times 6$ matrix representing the values of the pairwise comparison for the cocoa pod husk composite.

\begin{tabular}{ccccccc}
\hline Parameter & $\begin{array}{c}\text { Particulate } \\
\text { loading }\end{array}$ & $\begin{array}{c}\text { Initial } \\
\text { weight }\end{array}$ & $\begin{array}{c}\text { Particulate } \\
\text { weight }\end{array}$ & $\begin{array}{c}\text { Weight } \\
\text { of } \\
\text { matrix }\end{array}$ & $\begin{array}{c}\text { Weight } \\
\text { gained after } \\
150 \text { days }\end{array}$ & $\begin{array}{c}\text { Rate of } \\
\text { water } \\
\text { absorption }\end{array}$ \\
\hline Particulate loading & 0.450 & 0.730 & 0.470 & 0.160 & 0.260 & 0.231 \\
\hline Initial weight & 0.091 & 0.146 & 0.350 & 0.320 & 0.220 & 0.220 \\
\hline Particulate weight & 0.113 & 0.048 & 0.120 & 0.400 & 0.290 & 0.180 \\
\hline Weight of matrix & 0.227 & 0.036 & 0.024 & 0.081 & 0.180 & 0.150 \\
\hline $\begin{array}{c}\text { Weight gained after } \\
\text { 150 days }\end{array}$ & 0.165 & 0.023 & 0.015 & 0.016 & 0.037 & 0.210 \\
\hline $\begin{array}{c}\text { Rate of water } \\
\text { absorption }\end{array}$ & 0.0499 & 0.018 & 0.017 & 0.013 & 0.04 & 0.026 \\
\hline
\end{tabular}

Step 6 Calculate the criteria weight. This is achieved by adding all the elements in the row and dividing each by the number of criteria (Table 11). 
Table 11. The $6 \times 6$ matrix representing the values of the pairwise comparison for the cocoa pod husk composite.

\begin{tabular}{lllllll}
\hline Parameters $\rightarrow$ & $\begin{array}{l}\text { Particulate } \\
\text { loading }\end{array}$ & $\begin{array}{l}\text { Initial } \\
\text { weight }\end{array}$ & $\begin{array}{l}\text { Particulate } \\
\text { weight }\end{array}$ & $\begin{array}{l}\text { Weight } \\
\text { of } \\
\text { matrix }\end{array}$ & $\begin{array}{l}\text { Weight } \\
\text { gained after } \\
150 \text { days }\end{array}$ & $\begin{array}{l}\text { Rate } \\
\text { water } \\
\text { absorption }\end{array}$ \\
\hline $\begin{array}{l}\text { Criteria } \\
\text { weights } \rightarrow\end{array}$ & 0.383 & 0.225 & 0.192 & 0.157 & 0.061 & 0.021 \\
\hline
\end{tabular}

The numerical results are presented (Table 12) regarding the six parameters analyzed in the study.

Table 12. Normalised weight values for the current method and analytic hierarchy process (AHP) method.

\begin{tabular}{ccc}
\hline Parameter & Present method & AHP method \\
\hline Particulate loading & 0.399 & 0.383 \\
\hline Initial weight & 0.240 & 0.225 \\
\hline Particulate weight & 0.188 & 0.192 \\
\hline Weight of matrix & 0.109 & 0.157 \\
\hline Weight gained after 150 days & 0.045 & 0.051 \\
\hline Rate of water absorption & 0.019 & 0.021 \\
\hline
\end{tabular}

First, it was desired to understand the strength of the association between the two methods and correlation analysis was deployed. By using the MS Excel data analysis facility, a correlation value of 0.9884 was obtained, translated to 0.9769 in the coefficient of determination value. This result shows a high correlation value between the two methods and suggests that they are related. Furthermore, by taking the current method as the dependent variable, 0.9769 was obtained as the proportion of the variance of the proposed method, which is predictable from the AHP method. Thus, given the values of correlation and coefficient of determination of the current method compared with the AHP method, the competence of the present method to rank the parameters is confirmed. Further confirmation of the competence of the present method was made by the outcome of the AHP method being the same as the present method's results. Both methods yielded the positions (ranks) of the parameters as $1^{\text {st }}$ for particulate loading, $2^{\text {nd }}$ for initial weight, $3^{\text {rd }}$ for particulate weight, $4^{\text {th }}$ for the weight of the matrix, $5^{\text {th }}$ for weight gained after 150 days and $6^{\text {th }}$ for the rate of water absorption.

At $95 \%$ confidence level, the present method gives a value of 0.1482 while AHP method gives a value of 0.1371 . The higher value of the present method indicates that more assurance is attached to the present method than the AHP method that one can be $95 \%$ certain that the evaluated method contains the true mean for the population. Another statistical measure used 
is Kurtosis, which describes the level that the weights of the parameters clusters in the trails of the two methods, Kurtosis coefficients of 0.1675 and 0.3092 were obtained for the present method and the AHP method, respectively. Compared against normal kurtosis at 3, the two kurtosis coefficients are less than normal, which means that the data does not follow a normal distribution but some other types of distribution. The skewness coefficients are 0.8233 and 0.5996 for the present method and AHP method, respectively. This indicates that the present model is more skewed than the AHP method. Overall, the statistical test confirms the competence of the proposed method to evaluate the parameter and reliably rank them.

\section{CONCLUSIONS}

In the current study, six input parameters of water absorption during tests carried out on cocoa pod husk composite were examined for ranking and selection using the fuzzy analytic hierarchy process with the geometric mean feature. The parameters are the rate of water absorption, initial weight, weight gained after 150 days, particulate loading, particulate weight and weight of the matrix. Based on the results obtained from the present study, the following conclusions may be drawn:

1. The fuzzy analytic hierarchy process (FAHP) is an efficient ranking approach to select the best parameters to give attention to during the water absorption process.

2. FAHP indicates that the particulate loading, initial weight, particulate weight, weight of matrix weight gained after 150 days and rate of water absorption are important by ranks as $1^{\text {st }}, 2^{\text {nd }}, 3^{\text {rd }}, 4^{\text {th }}, 5^{\text {th }}$, and $6^{\text {th }}$, respectively, and by normalized values like $0.399,0.240$, $0.188,0.045$ and 0.0194 , respectively.

3. Further studies may be conducted on the hybridization of a decision tree diagram with the present structure of the fuzzy analytic hierarchy process.

\section{ACKNOWLEDGEMENT}

The author thanks the Chris Abiodun Ayanladun that assisted with the data preparation

\section{REFERENCES}

Azmin S.N.H.M., Hayat N.A.M., Nor M.S.M., 2020, Development and characterization of food packaging bioplastic film from cocoa pod husk cellulose incorporated with sugarcane bagasse fibre, Journal of Bioresources and Bioproducts, Vol. 5, No. 4, pp. 248-255. https://doi.org/10.1016/j.jobab.2020.10.003 
Aydemir D., Alsan M., Altuntas E. \& Ozte A. 2019, Mechanical, thermal and morphological properties of heat-treated wood-polypropylene composites and comparison of the composites with PROMETHEE method, Plastics, Rubber and Composites: Macromolecular Engineering, Vol. 48, No. 9, pp. 389-400. https://doi.org/10.1080/14658011.2019.1638132

Ayanladun C.A., Oke S.A. 2020. A sensitivity analysis of water absorption parameters of Theobroma cacao L. reinforced epoxy composites, Journal of Applied Science \& Process Engineering, Vol. 7, No. 2, pp. 587-610.

Bozbura F.T., Beskese A., 2007, Prioritization of organizational capital measurement indicators using fuzzy AHP, International Journal of Approximate Reasoning, Vol. 44, No. 2, pp. 124147.

Bozbura F.T., Beskese A., Kahraman C., 2007, Prioritization of human capital measurement indicators using fuzzy AHP, Expert Systems with Applications, Vol. 32, No. 4, pp. 1100-1112. Bozdag C.E., Kahraman C., Ruan D., 2003. Fuzzy group decision making for selection among computer integrated manufacturing systems, Computers in Industry, Vol. 51, pp. 13-29.

Chan F.T.S., Kumar N., 2007, Global supplier development considering risk factors using fuzzy extended AHP-based approach, Omega, Vol. 35, No. 4, pp. 417-431.

Chun K.S; Husseinsdyah S., Osman H., 2013, Modified cocoa pod husk filled polypropylene composites by using methacrylic acid; BioResources, Vol. 8, No.3, pp. 3260-3275

Chun K.S., Husseinsyah S., 2014, Agro waste-based composites from cocoa pod husk and polypropylene: Effect of filler content and chemical treatment, Journal of Thermoplastic Composite Materials, pp. 1-20, DOI: 10.1177/08 92705714563125

Chun K.S., Husseinsyah S., Yeng C.M., 2017. Torque rheological properties of polypropylene/cocoa pod husk composites, Journal of Thermoplastic Composite Materials, Vol. 30, No. 9, pp. 1217-1227. https://doi.org/10.1177/0892705715618743

Chun K.S., Yeng C.M., Hussiensyah S. 2018. Green coupling agent for agro-waste based thermoplastic composites, Vol. 39, No. 7, pp. 2441-2450. https://doi.org/10.1002/pc.24228

Daramola O.O., Akinwekomi A.D., Adediran A.A., Akindote-White O., Sadiku E.R. 2019. Mechanical performance and water uptake behaviour of treated bamboo fibre-reinforced highdensity polyethylene composites, Heliyon, Vol. 5, No. 7, e02028

Ebrahimi S., Bridgelall R., 2020, A fuzzy delphi analytic hierarchy model to rank factors influencing public transit mode choice: A case study, Research in Transportation Business \& Management, Article 100496, https://doi.org/10.1016/j.rtbm.2020.100496 
Ehi I.P., Bidemi J.K., Yahaya L.E. 2016, Kinetic studies on water absorption properties of cocoa-pod epoxy composites, Iranica Journal of Energy and Environment, Vol. 7, No. 1, pp. $48-51$

El-Shekeil, Y. A., Sapuan, S. M., \& Haron, M. 2014. Effect of fiber loading on tensile properties of cocoa pod husk fibers reinforced thermoplastic polyurethane composites. Applied Mechanics and Materials, Vol. $\quad$ 564, $\quad$ pp. 346-349. https://doi.org/10.4028/www.scientific.net/amm.564.346 https://www.igi-global.com/dictionary/fuzzy-analytic-hierarchy-process/51167 Ighravwe D.E. and Oke S.A., 2017. An integrated fuzzy analytical hierarchical process and fuzzy grey relational analytical model with VIKOR for maintenance system appraisal, Journal of Mechanical Engineering and Technology, Vol. 9, No. 1, pp. 1-20.

Imoisili P. E., Ezenwafor T.C., Attah-Daniel B.E. and Olusunle S.O.O. 2013a. Mechanical properties of cocoa-pod/epoxy composite: Effect of filler fraction, American Chemical Science Journal, Vol. 3, No. 4, pp. 526-531

Imoisili P.E., Etiobhio B.W., Ezenwafor. T.C., Attah-Daniels B.E., Olusunle S.O.O. 2013b, Physicochemical analysis of cocoa pod and its effect as a filler in polyester resin composite, International Journal of Science and Technology, Vol. 2 No. 1, pp. 89-93

Karthick R., Anbumalar V., Sutharson B., 2018, Comparative analysis of mechanical and water absorption behaviour of jute/glass fibre reinforced epoxy and polyester hybrid composites, International Journal of Materials Engineering Innovation, Vol.9, No.2, pp.82-93

Kusmono, Hestiawan H., Jamasri, 2020, The water absorption, mechanical and thermal properties of chemically treated woven fan palm reinforced polyester composites, Journal of Materials Research and Technology, Vol. 9, No. 3, pp. 4410-4420. https://doi.org/10.1016/j.jmrt.2020.02.065

Olabisi A.I., Adam A.N., Okechukwu O.M. 2016. Development and assessment of composite brake pad using pulverized cocoa beans shells filler, International Journal of Materials Science and Applications, Vol. 5, No. 2, pp. 66-78. DOI: 10.11648/j.ijmsa.20160502.16

Olatundun E.A., Borokini O.O., Betiku E., 2020, Cocoa pod husk-plantain peel blend as a novel green heterogeneous catalyst for renewable and sustainable honne oil biodiesel synthesis: A case of biowastes-to-wealth, Renewable Energy, https://doi.org/10.1016/j.renene.2020.11.131 Onyegiri I.E. and Oke S.A., 2016. An analytic hierarchical approach to building airline safety management systems, Erzincan University Journal of Science and Technology, Published by Erzincan University, Vol. 9, No. 3, pp. 147-163. 
Park S.W., Mesicek L., Shin J., Bae K., An K., Ko H., 2020. Customizing intelligent recommendation study with multiple advisors based on hierarchy structured fuzzy-analytic hierarchy process, https://doi.org/10.1002/cpe.5930

Puglia D., Dominici F., Badalotti M., Santulli C. and Kenny J.M. 2016. Tensile, thermal and morphological characterization of cocoa bean shells (CBS)/polycaprolactone-based composites, Journal of Renewable Materials, Vol. 4, No. 3, pp. 199-205. DOI: 10.7569/JRM.2016.634102

Raji A.O. and Oke S.A., 2020, Optimization of EDM for AA6061/10\%A12O3 AMMC using Taguchi schemes and analytical hierarchy process for weight determination, Kufa Journal of Engineering, Vol. 11, No. 3, pp. 42-61.

Sanyang M.L., Sapuan S.M., Haron M., 2017, Effect of cocoa pod husk filler loading on tensile properties of cocoa pod husk/polylactic acid green bio-composite films, The 2nd International Conference on Applied Science and Technology, 2017 (ICAST’17) pp. 020126-1-020126-6

Saxena M., Gupta M.K. 2018, Mechanical, thermal, and water absorption properties of hybrid wood composites, Proceedings of the Institution of Mechanical Engineers, Part L: Journal of Materials: Design and Applications, Vol. 233, No. 9, pp. 1914-1922

Song Q., Jiang P., Zheng S. 2021, The application of cloud model combined with nonlinear fuzzy analytic hierarchy process for the safety assessment of chemical plant production process, Process Safety and Environmental Protection, Vol. 145, pp. 12-22.

https://doi.org/10.1016/j.psep.2020.07.048

Wei Z., Ma X., Zhan P., Tian H., Li K. 2020, Flavor quality evaluation system of Xinjiang milk knots by using SOM neural network and the fuzzy AHP, Vol. 8, No. 4, pp. 2088-2093. https://doi.org/10.1002/fsn3.1501

Yu Z., Zeng H., Min X., Zhu X. 2020. High-performance composite photocatalytic membrane based on titanium dioxide nanowire/graphene oxide for water treatment, Applied Polymer, Vol. 137, No. 12, 48488, https://doi.org/10.1002/app.48488. 